\title{
CGA codons multiplex PCR in rapid diagnosis of retinoblastoma
}

\author{
Gandra Mamatha, Biju Joseph, Mahesh Palanivelu Shanmugam*, Govindasamy Kumaramanickavel \\ SN ONGC, Departments of Genetics and Molecular Biology, *Dept of Medical Retina, Medical and Vision Research Foundations, \\ Sankara Nethralaya, Chennai - 600 006, India
}

BACKGROUND: Multiplex polymerase chain reaction allows amplification of multiple target sequences of a genome under identical conditions in a single tube. This "oneshot" polymerase chain reaction detection is time and cost effective when large or multiple genes, with many target fragments are investigated. This is applicable for retinoblastoma susceptibility gene having 27 exons with recurrent mutations reported at most of the 12 CGA codons.

MATERIALS AND METHODS: Multiplex polymerase chain reaction assay for the amplification of 12 CGA codons, which constitutes about $50 \%$ of retinoblastoma susceptibility gene mutations has been designed. The time and cost (includes only reagent cost) involved in both multiplex and uniplex polymerase chain reaction was also calculated. RESULTS: Twelve CGA codons were multiplexed in 5 instead of 12 uniplex polymerase chain reactions, which took 36 hours and 9.78 US\$ whereas multiplex polymerase chain reaction took 15 hours and 6.88 US\$. Multiplex polymerase chain reaction method saved $58.3 \%$ of time and $29.6 \%$ of cost over uniplex polymerase chain reaction.

CONCLUSION: Saving time by more than half and cost by nearly a third would help clinicians and geneticists while counseling retinoblastoma patients.

Key words: CGA codons, multiplex polymerase chain reaction, retinoblastoma, $\mathrm{RB} 1$ gene and rapid diagnosis.

\section{Introduction}

Retinoblastoma is a rare tumor that arises when both RB1 gene alleles are mutated. The developing retina has $4 \times 10^{6}$ cells, but only about 1 in $10^{6}$ cells actually give rise to a tumor cell. Mutations in RB1 usually result in disruption of the protein product and cause retinoblastoma. ${ }^{[1,2]}$

One of the major goals in treatment of patients with retinoblastoma is early detection of retinoblastoma that helps in saving the vision in the affected eye. Despite the use of modern molecular techniques, there have been several obstacles to achieve the goal, because the retinoblastoma gene is very large and mutations occur throughout the gene with no single 'hot spot'. ${ }^{[3]}$ Five to 8 percentof mutations in RB1 gene can be observed cytogenetically, which includes predominantly deletions but rarely insertions and translocations. ${ }^{[3]}$ Remaining alterations are submicroscopic, which includes nonsense mutations, frame-shift mutations, missense mutations, in frame deletions, intron nucleotide change (alters splicing), loss of heterozygosity, or methylation of the promoter region.

From various reports throughout the world it is found that in DNA mutations, non-sense and frame-shift mutations occur in $78 \%$ of retinoblastoma patients, intronic changes in $12 \%$ of patients, missense and small in-frame deletions in $8 \%$ of patients and nucleotide changes in the promoter region in $2 \%$ of patients. ${ }^{[4]}$ Nonsense and frame-shift mutations result in premature termination of translation resulting in a truncated protein product, which cannot regulate the cell cycle. These mutations are more disruptive to protein function than other types of mutations. ${ }^{[4,5]}$ Cowell et $a^{[6]}$ has shown that the most common point mutation in the RB1 gene in retinoblastoma tumors is $\mathrm{C}->\mathrm{T}$ transition and majority of these occur in CGA codons. As a result of this mutation, a TGA stop codon is generated directly which has been predicted to result in the absence of a functional protein. Fourteen CGA codons in the RB1 gene has been analysed for mutations in 113 patients 
with bilateral retinoblastoma. Six of these sites, C->T mutations in CGA codons alter a restriction enzyme site, which makes their identification relatively straightforward. ${ }^{6]}$

As majority of single base substitutions (76\%) in RB1 gene are recurrent $\mathrm{CpG}$ transitions at 12 of the 15 CGA codons within the open reading frame,,$^{[4,7]}$ they can be identified by a relatively quick survey of the CGA codons.

A mPCR (multiplex polymerase chain reaction) method for the amplification of 12 CGA codons of RB1 gene was designed, that allows rapid identification of RB1 mutations. The main advantage of MPCR is speed of analysis followed by economy on sample and reagents than UPCR (uniplex polymerase chain reaction) performed; less Taq polymerase, dNTPs and buffer; consumables including DNA. Simplicity of the method and sensitivity of the detection adds to the advantages of $\mathrm{mPCR}$. According to this principle, we designed an extensive $\mathrm{MPCR}$ reaction for $12 \mathrm{CGA}$ codons within RB1. Using this approach, we were able to save both time and cost.

\section{Materials and Methods}

The laboratory technique includes DNA extraction and multiplex PCR followed by $2 \%$ agarose gel electrophoresis.

\section{DNA Extraction}

DNA has been extracted from the venous blood collected from unrelated control subjects by standard phenol chloroform method.

\section{Uniplex PCR}

Exons 1-27 of RB1 gene were PCR amplified in individual reactions containing 100-150 ng DNA, 4-6 pM of primers, $160 \mathrm{nM}$ of dNTPs, 1 X PCR buffer and $0.6 \mathrm{U}$ of Taq DNA polymerase (Bangalore Genie, Ltd) in a 20- $\mu \mathrm{L}$ reaction. The thermal profile consisted of initial denaturation at $94^{\circ} \mathrm{C}$ for 5 minutes; then 30-35 cycles consisting of denaturation at $94^{\circ} \mathrm{C}$ for 45 seconds; annealing at the specific temperature for 60 seconds and extension at $72^{\circ} \mathrm{C}$ for 90 seconds. The specific primers sequences flanking the exonic regions were obtained from the Genome Data Bank. PAGE purified primers from Banglore Genie were used for PCR amplification. PCR was carried out in PE 2700 thermal cycler. The amplified products were electrophoresed in $2 \%$ agarose with ethidium bromide stain and visualized using Amersham Pharmacia Gel documentation system and analyzed using Image Master VDS.

\section{Multiplex PCR}

PCR for all 27 exons of RB1 gene was previously standardized in our laboratory as individual reactions. For multiplex PCR, 12 CGA codons were separated in to five groups as given in Table 1 based on product size and annealing temperature at which PCR for individual exon has been standardized.

For all amplifications $20 \mu \mathrm{l}$ reaction mixture was prepared using $100 \mathrm{ng}$ of genomic DNA, $4 \mathrm{pM}$ of all primers, $3 \mu$ l dNTPs ( $40 \mathrm{nM}$ ), $4 \mu \mathrm{l}$ PCR buffer and $0.6 \mathrm{U}$ of Taq DNA polymerase. The PCR was carried out in the thermal cycler-PE 2700. The amplified products were separated on $2 \%$ agarose gel electrophoresis, captured by gel documentation system ImageMaster ${ }^{\circledR}$ VDS, Pharmacia Biotech using the Liscap software and analysed using Image master Total lab gel documentation system. The time and reagents consumed for uniplex and multiplex PCR was calculated.

\section{Results}

\section{Uniplex PCR}

Polymerase chain reaction has been standardized for 12 exons of RB1 gene containing CGA codons at specific annealing temperatures in $20 \mathrm{~mL}$ reaction volume. The time and cost consumed for the amplification of 12 CGA codons by uPCR was calculated to be 36 hours and 9.78 US\$ [Table 2].

\begin{tabular}{|c|c|c|c|}
\hline Groups & Exons & $\begin{array}{l}\text { Annealing temperature } \\
\text { (No. of cycles) }\end{array}$ & $\begin{array}{l}\text { Product size } \\
\text { (bp) }\end{array}$ \\
\hline 1 & $5 \& 18$ & $\begin{array}{c}45^{[0]} \mathrm{C} \\
(35 \text { cycles })\end{array}$ & $\begin{array}{c}5-177 \\
18-248\end{array}$ \\
\hline 2 & 8 & $\begin{array}{c}43^{[0]} \mathrm{C}+44^{[0]} \mathrm{C}+44^{[0]} \mathrm{C} \\
(10+15+10)\end{array}$ & $8-243$ \\
\hline 3 & $1,13,23 \& 27$ & $\begin{array}{c}49^{[0]} \mathrm{C}+50^{[0]} \mathrm{C}+51^{[0]} \mathrm{C} \\
(15+10+15)\end{array}$ & $\begin{array}{l}11-351 \\
13-236 \\
23-393\end{array}$ \\
\hline 4 & $10,12 \& 17$ & $\begin{array}{c}45^{[0]} \mathrm{C}+46^{[0]} \mathrm{C}+47^{[0]} \mathrm{C} \\
(15+10+15)\end{array}$ & $\begin{array}{c}10-259 \\
12-18217-494\end{array}$ \\
\hline 5 & $14 \& 15$ & $\begin{array}{c}59^{[0]} \mathrm{C} \\
(35 \text { cycles })\end{array}$ & $14-26515-225$ \\
\hline
\end{tabular}




\section{Multiplex PCR}

The technique of multiplex PCR for 12 CGA codons of RB1 gene has been optimized under the conditions given in Table 1. The time and cost consumed for the amplification of 12 CGA codons by $\mathrm{MPCR}$ was calculated to be 15 hours and 6.88 US\$. MPCR is found to be cost and time saving when compared to UPCR, saving $58.3 \%$ of time and $29.6 \%$ of cost.

\section{Discussion}

Recognition of the retinoblastoma gene and the technology to identify point mutations within will make it possible to offer antenatal diagnosis to an increasing number of patients. These advances at the molecular level will help to determine whether a new mutation is of somatic or germinal origin and thereby identify gene carriers. UPCR strategies are useful for mutational screening of small genes or genes with mutational hotspots. But these strategies will not be cost or labour efficient when large or multiple genes, with many target sequences are involved. In addition, such an approach is limited by sample quantity. Considerable saving of reagents, time and effort can be achieved by simultaneously amplifying multiple sequences in a single reaction, a process referred to as $\mathrm{MPCR}$. The large size of the RB1 gene - $180 \mathrm{~kb}$ with an open reading frame of $2.7 \mathrm{~kb}$ and lack of mutation hotspots necessitates a mPCR based strategy in developing rapid DNA based diagnostic services for retinoblastoma. At the vitreous and retina department, Sankara Nethralaya, on an average 75 retinoblastoma patients are seen in a year. Nearly half of these families are one-child families. ${ }^{[8]} \mathrm{A}$ rapid molecular diagnostic method for retinoblastoma susceptibility gene will be useful for these families in taking a decision about having another child. Du and Gallie used quantitative fluorescent mPCR for mutational screening of RB1 gene and detected mutations in $50 \%$ of retinoblastoma patients screened..$^{[9]}$ In a study of pituitary tumours, mPCR was used for identification of

Table 2: Time and cost saved by mPCR over UPCR

\begin{tabular}{lcc}
\hline Strategy for PCR & Time (Hrs) & Cost (US \$) \\
\hline uPCR (12 CGA codons) & $36(3 \times 12)$ & 9.78 \\
mPCR (12 CGA codons) & $15(3 \times 5)$ & 6.88 \\
Savings $(\%)$ & $58.3 \%$ & $29.6 \%$ \\
\hline
\end{tabular}

homozygous deletion of exons 20-24 of RB1 gene from pituitary tumour DNA that failed to express retinoblastoma protein. ${ }^{[10]}$ Lohmann et al analysed DNA from peripheral blood of 24 unrelated bilateral retinoblastoma patients without gross structural abnormalities by MPCR and polyacrylamide gel electrophoresis. ${ }^{[11]}$ Screening of $26 \%$ of the RB1 coding region identified germline mutations 3 out of 24 bilateral retinoblastoma patients. $\mathrm{MPCR}$ followed by heteroduplex analysis and sequencing has been used as an efficient screening method for retinoblastoma. ${ }^{[12]}$

RB1 gene is composed of 27 exons with no mutation hotspots. But majority of single base substitutions (76\%) in RB1 gene are recurrent $\mathrm{CpG}$ transitions at 12 of the 15 CGA codons within the open reading frame (in the exons 8 (2 sites), 10, 11, 13, 14 (2 sites), 15, 17 (2 sites), 18 and 23) of RB1 gene. ${ }^{[3,7]}$ It is assumed that mPCR strategy for the CGA containing exons will offer an advantage for the rapid mutational screening and characterization of the mutational spectra of RB1 gene in retinoblastoma patients with considerable savings in time and reagents. Hence, based on diagnostic importance of the disease we designed $\mathrm{MPCR}$ method for the amplification of 12 CGA codons (exon 5,8,10 $15,17,18,23$ and 27 ) as more than $50 \%$ of the RB1 gene mutations are reported in them.

Initially the 12 exons of RB1 gene were PCR amplified in individual reactions. For mPCR, 12 CGA codons were separated in to five groups based on product size and annealing temperature at which PCR for individual exon has been standardized. Each group includes exons with nearby annealing temperature but with different product size. Parameters like annealing temperature, number of cycles were varied to obtain amplified products with high yield. The optimization of mPCR posed several difficulties. The presenceof more than one primer pair in the MPCR increases thechance of obtaining spurious amplification products, primarilybecause of the formation of primer dimers. ${ }^{[13]}$ These nonspecificproducts may be amplified more efficiently than the desired target, consuming reaction components and producing impaired rates ofannealing and extension. To overcome the problem of non-specific amplification we initially altered PCR components such as PCR buffer constituents, dNTPs and enzyme concentrations overthose reported for most uniplex PCRs but there was no improvement 
in the yield, later when the annealing temperature was increased to one degree above the actual temperature at which uniplex PCR has been standardized for an individual exon, specific bands were obtained without any non-specific amplification.

The CGA codon containing exons were multiplexed in five reactions [Table 2, Figure 1] thus saving 21 hours (58.3\%) of PCR time. The cost savings involved in CGA codon mPCR is 2.9 US $\$$ (29.6\%). Our calculations were based on the assumption that the time for one PCR run was 3 hours and only the reagent cost is included. In this way time for amplifying 12 exons in individual reactions were 36 hours. The multiplexed strategy enabled us to save 21 hours by amplifying twelve exons in five reactions. The amplification of exons 11, 13, 23 and 27 in the same PCR run saved 9 hours. Exons 10 , 12 and 17 were amplified at $45^{\circ} \mathrm{C}+46^{\circ} \mathrm{C}+47^{\circ} \mathrm{C}$ in individual reactions saving 6 hours (exon 8 could not be multiplexed because the product size and annealing temperature did not fit in to any of the group). During the last decade, a number of studies have demonstrated the practicality of identifying RB1 gene mutations using

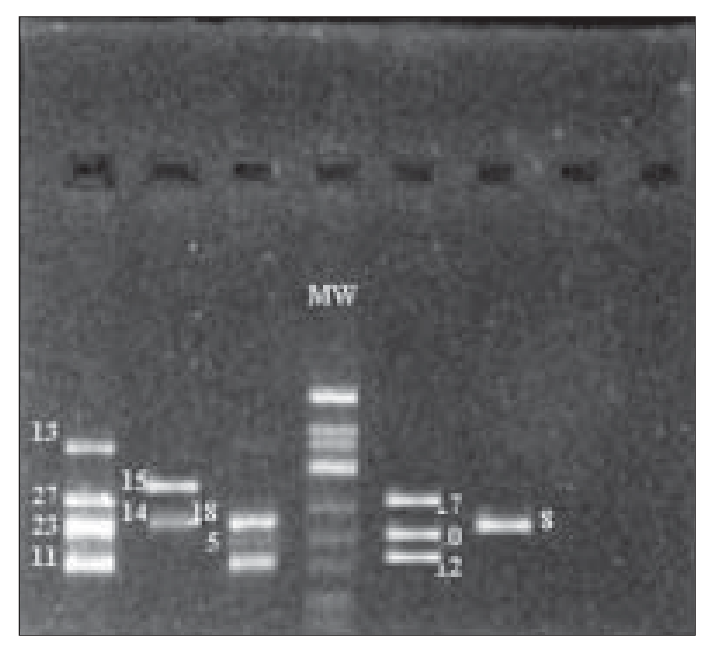

Figure 1: Multiplex PCR amplification of 12 CGA codons within RB1 gene on $2 \%$ agarose gel

Lane 1: multiplex PCR products of RB1 exons 13 (539 bp), 27 (347 bp), 23 (280 bp) and 11 (205bp)

Lane 2: multiplex PCR products of RB1 exons 15 (360 bp) and 14 (265 bp)

Lane 3: multiplex PCR products of RB1 exons 18 (248 bp) and 5 (177 bp)

Lane 4: molecular weight marker (Hinf I digest)

Lane 5: multiplex PCR products of RB1 exons 17 (351 bp), 10 (233 bp) and 12 (185 bp)

Lane 6: multiplex PCR products of RB1 exon 8 (243 bp)
mPCR. As per our knowledge, this is for the first time mPCR method has been optimized for CGA codons of RB1 gene; the purpose of our study is to facilitate rapid identification of RB1 mutations. We first screen CGA codons, which have $40-50 \%$ of mutations; if no mutation is detected then rest of the exons within the RB1 gene will be screened. Optimization of mPCRs that are designed for simultaneousamplification of multiple targets may prove beneficial for the RB1 diagnostics, which could have implications in genetic counselling.

\section{Acknowledgements}

We acknowledge the Department of Bio-technology, Government of India for their funding for the project titled "'Developing DNA diagnostic methods for retinoblastoma and its application in genotype - phenotype correlation". Ref No. (BT/ PR 1607/Med / 09/250/99(HG).

\section{References}

1. Abramson DH, Tarone RE, Kleinerman RA. Hereditary retinoblastoma, lipoma and second primary cancers. J Natl Cancer Inst 1997;89:83-4.

2. Zhu X, Dunn JM, Goddard AD, Squire JA, Becker A, Phillips RA, et al. Mechanism of loss of heterozygosity in retinoblastoma. Cytogenet Cell Genet 1992;59:248-52.

3. Lohmann DR. RB1 gene mutations in retinoblastoma. Human Mutat 1999;14:283-8.

4. OMIM: http:// www. gdb. org /omimdoc/omimtop.html.

5. Murphree AL. Molecular genetics of retinoblastoma. Ophthalmol Clin North Am 1995;8:155-66.

6. Cowell JK, Smith T, Bia B. Frequent constitutional C to T mutations in CGA-arginine codons in the RB1 gene produce premature stop codons in patients with bilateral (hereditary) retinoblastoma. Eur J Human Genet 1994;2:28190.

7. Hogg A, Bia B, Onadim Z, Cowell JK. Molecular mechanisms of oncogenic mutations in tumors from patients with bilateral and unilateral retinoblastoma. Proc Natl Acad Sci USA 1993;90:7351-5.

8. Harini R, Ata-ur-Rasheed M, Shanmugam MP, Amali J, Das D, Kumaramanickavel G. Genetics of retinoblastoma: A cytogenetic and segregation analyses profile of 81 patients from a referral hospital in southern India. Indian $\mathrm{J}$ Ophthalmol 2001;49:37-42.

9. Du C, Gallie BL. Detection of RB1 mutations by using quantitative fluorescent multiplex PCR. Chung Hua I Hsueh I Chuan Hsueh Tsa Chih 1999;16:386-9.

10. Simpson DJ, Hibberts NA, McNicol AM, Clayton RN, Farrel WE. Loss of $\mathrm{pRb}$ expression in pituitary adenomas is associated with methylation of the RB1 CpG island. Cancer Res 2000;60:1211-6.

11. Lohmann D, Horsthemke B, Gillessen KG, Stefani FH, Hofler H. Detection of small RB1 gene deletions in retinoblastoma by multiplex PCR and high-resolution gel electrophoresis. Hum Genet 1992;89:49-53. 
12. Lohmann DR, Gerick M, Brandt B, Oelschlager U, Lorenz $\mathrm{B}$, Passarge $\mathrm{E}$, et al. Constitutional RB1 gene mutations in patients with isolated unilateral retinoblastoma. Am J Hum Genet 1997;61:282-94.
13. Brownie J, Shawcross JS, Theaker J, Whitcombe D, Ferrie R, Newton C, et al. The elimination of primer-dimer accumulation in PCR. Nucleic Acids Res 1997;25:323541.

\title{
First National Workshop on Microdeletion FISH
}

\author{
Workshop Date: August $7^{\text {th }}$ to $12^{\text {th }}, 2006$
}

Place: Dept. of Reproductive Biology, AlIMS, New Delhi-110029

Areas to be covered: FISH Probe Cloning, BAC DNA Isolation, Probe Labeling

by Nick Translation method, Interphase \& Metaphase FISH on microdeletion cases and control

Pre-Registration: By 30/04/2006 with short cv

Registration: By 01/07/2006 with Registration Fee

Registration Fee: Rs. 5000/- (government organization) or

Rs. 10000/- (non-government organization)

\section{For more information please contact:}

Dr. Ashutosh Halder, Dept of Reproductive Biology, AllMS, New Delhi-110029, India

Tel: 011-26593304 ext. 4211; Mobile: 9313309579 ; Fax: 011-26588663

E-mail: ashutoshhalder@yahoo.co.in; ashutoshhalder@gmail.com or

Visit Web Site at http://www.aiims.ac.in/conf/microdelfish.html or www.aiims.ac.in click conference then microdeletion FISH 